\title{
Author Correction: Meridional heat transport variability induced by mesoscale processes in the subpolar North Atlantic
}

\author{
Jian Zhao (iD ${ }^{1}$, Amy Bower ${ }^{1}$, Jiayan Yang ${ }^{1} \&$ Xiaopei Lin²
}

Correction to: Nature Communications https://doi.org/10.1038/s41467-018-03134-x, published online 19 March 2018

The original version of this Article omitted the author N. Penny Holliday from the National Oceanography Centre, European Way, Southampton SO14 3ZH, UK.

Consequently, the following was originally omitted from the Acknowledgements: 'N.P.H. and the JR302 cruise were funded through the UK Natural Environment Research Council programmes UK OSNAP (NE/K010875/1), RAGNARRoCC (NE/K002511/1) and the Extended Ellett Line (National Capability)'. The corrected version of the Acknowledgements also removes the following from the original version: 'The Zonally Accumulated Heat Transport in observation was calculated by N.P.H. from the National Ocean Center, United Kingdom'.

Additionally, the following was originally omitted from the Author Contributions: 'N.P.H. calculated the observed Zonally Accumulated Heat Transport along the OSNAP east section'.

This has been corrected in both the PDF and HTML versions of the Article.

Published online: 14 June 2018

Open Access This article is licensed under a Creative Commons Attribution 4.0 International License, which permits use, sharing, adaptation, distribution and reproduction in any medium or format, as long as you give appropriate credit to the original author(s) and the source, provide a link to the Creative Commons license, and indicate if changes were made. The images or other third party material in this article are included in the article's Creative Commons license, unless indicated otherwise in a credit line to the material. If material is not included in the article's Creative Commons license and your intended use is not permitted by statutory regulation or exceeds the permitted use, you will need to obtain permission directly from the copyright holder. To view a copy of this license, visit http://creativecommons.org/licenses/by/4.0/.
}

(C) The Author(s) 2018

\footnotetext{
${ }^{1}$ Woods Hole Oceanographic Institution, Woods Hole, MA 02543, USA. ${ }^{2}$ Physical Oceanography Laboratory/CIMST, Ocean University of China and Qingdao National Laboratory for Marine Science and Technology, Qingdao 266100, China. Correspondence and requests for materials should be addressed to J.Z. (email: jzhao@whoi.edu) or to X.L. (email: linxiaop@ouc.edu.cn)
} 